\title{
Neural expression and post-transcriptional dosage compensation of the steroid metabolic enzyme $17 \beta-$ HSD type 4
}

Sarah E London ${ }^{1,2,3,5^{*}}$, Yuichiro Itoh ${ }^{2,3}$, Valentin A Lance ${ }^{2}$, Petra M Wise ${ }^{2}$, Preethika S Ekanayake ${ }^{2}$, Randi K Oyama ${ }^{2}$, Arthur P Arnold ${ }^{1,2,3}$, Barney A Schlinger ${ }^{1,2,3,4}$

\begin{abstract}
Background: Steroids affect many tissues, including the brain. In the zebra finch, the estrogenic steroid estradiol $\left(E_{2}\right)$ is especially effective at promoting growth of the neural circuit specialized for song. In this species, only the males sing and they have a much larger and more interconnected song circuit than females. Thus, it was surprising that the gene for 17ß-hydroxysteroid dehydrogenase type 4 (HSD17B4), an enzyme that converts $E_{2}$ to a less potent estrogen, had been mapped to the $Z$ sex chromosome. As a consequence, it was likely that HSD17B4 was differentially expressed in males (ZZ) and females (ZW) because dosage compensation of $Z$ chromosome genes is incomplete in birds. If a higher abundance of HSD17B4 mRNA in males than females was translated into functional enzyme in the brain, then contrary to expectation, males could produce less $E_{2}$ in their brains than females.

Results: Here, we used molecular and biochemical techniques to confirm the HSD17B4 Z chromosome location in the zebra finch and to determine that HSD17B4 mRNA and activity were detectable in the early developing and adult brain. As expected, HSD17B4 mRNA expression levels were higher in males compared to females. This provides further evidence of the incomplete $Z$ chromosome inactivation mechanisms in birds. We detected HSD17B4 mRNA in regions that suggested a role for this enzyme in the early organization and adult function of song nuclei. We did not, however, detect significant sex differences in HSD17B4 activity levels in the adult brain.

Conclusions: Our results demonstrate that the HSD17B4 gene is expressed and active in the zebra finch brain as an $E_{2}$ metabolizing enzyme, but that dosage compensation of this Z-linked gene may occur via post-transcriptional mechanisms.
\end{abstract}

\section{Background}

Steroids have profound effects on the brain. In the zebra finch (Taeniopygia guttata), regulation of the estrogenic steroid estradiol $\left(E_{2}\right)$ within the zebra finch brain may have functional consequences for song behavior. In zebra finches, males sing but females do not. Males also have a larger and more interconnected set of brain areas, or nuclei, specialized to learn and produce song than females [1]. Early in development, $E_{2}$ masculinizes the song circuit required for song production and in

\footnotetext{
* Correspondence: slondon@illinois.edu

${ }^{1}$ Interdepartmental Program in Neuroscience, University of California at Los Angeles, Los Angeles, CA, USA
}

adulthood, the function of song areas can be altered by changes in $\mathrm{E}_{2}$ after song experience [2-5].

The gonads do not supply the steroids that direct masculinization of the song circuit, but the brain may be an essential source of $E_{2}$ both during development and in adulthood [6-24]. It is still unclear, however, how steroids produced in the brain act on the song system [17,24-28]. Therefore, two non-exclusive theories have been proposed to explain the origin of sex differences in this system: sex differences are caused by local differences in steroid synthesis in or near the song control circuit $[6,7,11-13,17]$, and sex differences are caused by the differential effect of genes localized to sex chromosomes $[29,30]$. 
Evidence exists to support both theories. Many of the major steroid -producing and -transducing factors that can act on the song circuit are present in the zebra finch brain $[6,7,10,11,18,19,31-37]$. For example, early developmental $E_{2}$ administration to females acts in the brain to induce a masculine song circuit and the closer the source of steroids is to a song nucleus the more potent its effect, cultured brain slices produce $E_{2}$ and manipulations of $E_{2}$ levels and estrogen receptor action in these slices prevent full masculinization of song circuitry, and the $E_{2}$-synthetic enzyme aromatase is present in presynaptic terminals within major song nuclei; in fact, in adult male zebra finches, the brain is the major source of $E_{2}[2,8,9,15,16,38-42]$. On the other hand, in vivo manipulations of $\mathrm{E}_{2}$ synthesis and action in males does not consistently significantly de-masculinize the song system, the song circuit in genetic females is not masculinized by the presence of functional steroidsecreting testes, and the song nuclei within the male hemisphere of a naturally-occurring gynandromorph (one half genetically male, one half genetically female) are larger than those in the genetically female hemisphere [22,25,28,42-46]. Although in some cases, these findings are partially consistent with the neural steroid synthesis hypothesis, they primarily suggest that genetic differences between males and females contribute to the masculine development of the song system.

Indeed, in mammals and in zebra finches, data is accumulating that male brain cells are fundamentally different than female cells by virtue of their different complement of sex chromosomes: $\mathrm{XX} / \mathrm{XY}$ in mammalian females and males, and $\mathrm{ZW} / \mathrm{ZZ}$ in avian females and males, respectively. There is evidence that genes on the sex chromosomes might influence sexual differentiation of the zebra finch song system [25,30,47-50]. The potential for sex chromosome genes to display sex differences in expression levels is especially high in the zebra finch because sex chromosome dosage compensation is largely ineffective in birds at the mRNA level [51-53].

Here, we examine $17 \beta$-hydroxysteroid dehydrogenase type 4 (HSD17B4), a steroidogenic enzyme that converts $E_{2}$ to a less potent estrogen, estrone $\left(E_{1}\right)$. Inasmuch as HSD17B4 is present and active in particular brain regions, it could regulate the local concentrations of $E_{2}$. This could impact the organization and function of the song circuit $[12,13,24,50,54-56]$. Previous experiments have shown evidence that HSD17B4 is localized to the $\mathrm{Z}$ chromosome and has a male-biased sex difference in brain expression levels across development [50,57]. HSD17B4 therefore represents a convergence of the steroidal and genetic theories of song system sexual differentiation. All of this also suggests, however, that $E_{2}$ might be less available to the male brain, a prediction contrary to findings that $\mathrm{E}_{2}$ masculinizes the song system.

We therefore used several techniques to examine HSD17B4 DNA, mRNA, and enzyme activity in male and female zebra finch brains. We used posthatch day 5 (P5) and adult birds because at both ages, $\mathrm{E}_{2}$ meaningfully impacts the song system. P5 is within the period when steroid administration has the greatest masculinizing effect on song nuclei, other steroid-synthesizing genes are expressed in the brain at this early age, and it is just prior to the earliest emergence of identifiable song control nuclei $[6,11,38,58,59]$. Thus expression of HSD17B4 at this early age could alter the local steroid environment that contributes to the initial organization of song nuclei. In adulthood, measures in song nuclei show the potential for rapid and synaptic regulation of estradiol synthesis, which could have functional consequences for song production and perception [2-5]. Our results show that HSD17B4 is sexually dimorphic and could impact both developing and mature song nuclei, consistent with a previous report, and that dosage compensation of HSD17B4 gene may act at a post-transcriptional level [50]. It will require further study to understand how these dosage compensation mechanisms affect neural steroid production, and therefore organization and function of the sexually dimorphic song control circuit.

\section{Results}

\section{Zebra finch HSD17B4 gene and CDNA sequences}

We used two independently cloned cDNAs as probes for the molecular experiments. The clone used for Bacterial Artificial Clone (BAC) library screening, and Northern and Southern blot hybridizations was an Expressed Sequence Tag (EST; GenBank Accession No. CK313884) cloned by the Songbird Neurogenomics Initiative (SoNG) as part of its transcriptome project [60]. Based on alignment with the zebra finch HSD17B4 gene model (below), this cDNA includes sequence beginning at exon 14 through the end of the transcript and therefore spans part of the hydratasedehydrogenase epimerase (HDE) domain, the entire sterol carrier protein 2 (SCP2) domain $[61,62]$ and the 3'-UTR (Figure 1). The comparison of zebra finch, chicken, human, mouse and zebra fish predicted amino acid sequences showed that there is high conservation along HDE and SCP2 domains (range of 56\%-90\% identity across both domains for this subset of species comparisons; Figure 1).

Prior to the SoNG EST project, we had cloned a HSD17B4 cDNA that we used as the riboprobe template for our brain in situ hybridization experiments. The sequence of this clone spans almost exactly the same region of gene as the SoNG EST except that it begins 


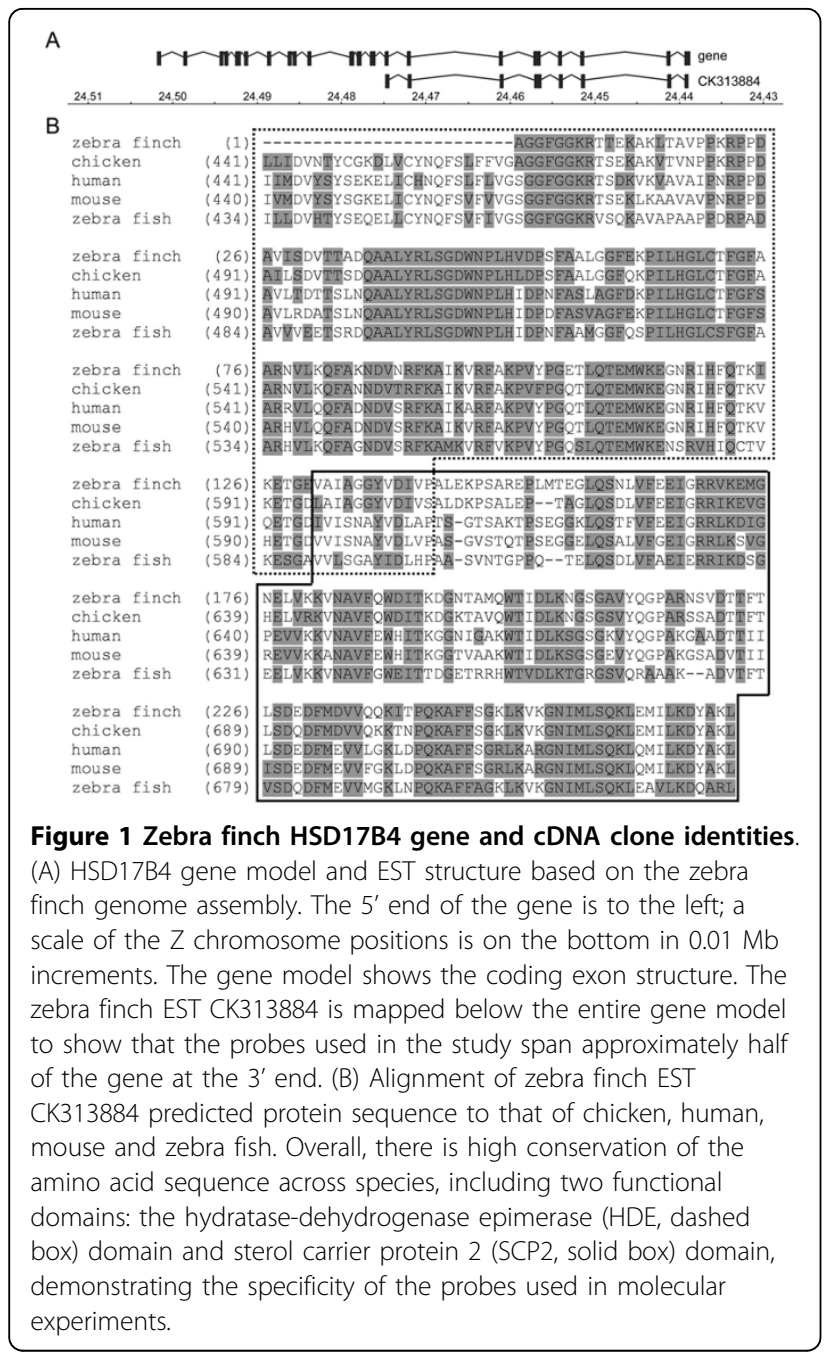

$35 \mathrm{bp}$ after the EST at the 5' end of the gene and extends 55 bp further than the EST at 3' end. The high level of cDNA sequence conservation across species, including essential functional domains, demonstrated that both cDNAs used in subsequent molecular experiments are almost certainly specific for HSD17B4.

To further confirm that the molecular tools we used were indeed HSD17B4, we examined the cDNA clone sequences in relation to the gene sequence in the zebra finch genome assembly. Using the Apollo Genome Annotation Curation Tool, we manually annotated the zebra finch DNA sequence from the genome assembly, the nucleotide sequences of the two clones we used for experiments, and other available transcript sequences to confirm the HSD17B4 gene model [63,64](Figure 1). In the zebra finch assembly, the gene was mapped to chromosome Z:24,439,644-24,502,076. As in the human gene, the zebra finch gene model contains 24 coding exons, although we were unable to predict the precise boundaries of the 5'-untranslated (UTR) region of the zebra finch gene using existing sequence data [65].

\section{Confirmation of $\mathbf{Z}$ chromosome localization}

We examined the intensity of hybridization on a Southern blot that contained male and female genomic DNA and to test if we could detect a sex difference in HSD17B4 gene abundance. To control for the possibility that gene products derived from one enzyme digestion could provide spurious results, we digested the genomic DNA with two enzymes, HaeII and HindIII, which results in two different banding patterns (Figure 2A). The male and female DNA showed virtually the same pattern of hybridized DNA fragments when digested with the same enzyme, with the exception of lightappearing bands that are visible in the male sample but not the female sample (Figure 2A). In cases when DNA products are visible in both male and female samples, the male bands appear to show darker hybridization signals than the corresponding female band. This suggests that the apparent sex difference in DNA digest products likely reflects the detection limit of the blot, not a biological difference in DNA content. The fact that hybridization showed stronger signals in the male DNA, almost twice the signal as from hybridization to the female DNA sample, suggests more copies of the gene in males than females (Figure 2A). The lack of a female-specific

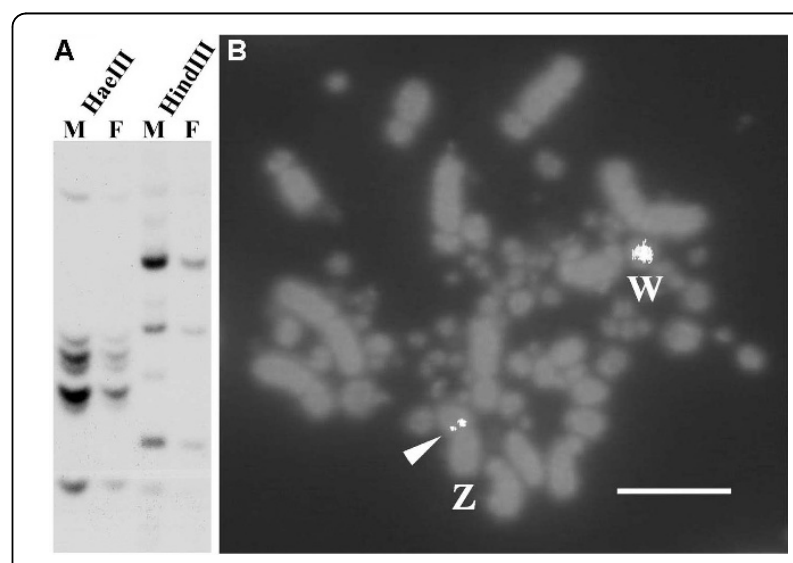

Figure 2 Males have more $Z$ chromosome-linked HSD17B4 DNA. (A) Southern blot hybridization of Haell and Hindlll digested genomic DNA from male (M) and female (F) of zebra finch probed with ${ }^{32}$ P-labeled zebra finch HSD17B4 EST CK313884. In both digest samples, the blot showed bands of stronger signal in males than females, suggesting $Z$ chromosome linkage of HSD17B4. (B) $Z$ chromosome localization of HSD17B4 sequence confirmed by FISH analysis. Individual fluorescently stained chromosomes are in the background, and two distinct, sharp hybridization signals over the Z chromosome show label on the two copies of the HSD17B4 gene (arrowhead). The Z-linked 094L04 BAC probe encoding HSD17B4 also cross-hybridized to the $W$ chromosome, suggesting that it contains repetitive sequences such as ZBM that are present on both $Z$ and $W$ [67]. Scale bar $=10 \mu \mathrm{m}$. 
band in the Southern blot also suggests that the W chromosome does not have sequences homologous to CK313884.

To confirm the $\mathrm{Z}$ chromosome localization of HSD17B4 gene, we used the EST to first screen a zebra finch BAC library http://www.genome.arizona.edu to isolate a larger genomic clone to be used as the Fluorescent In situ Hybridization (FISH) probe [52]. The selected BAC clone, 094L04, encompassed HSD17B4 and mapped to the short arm of zebra finch $\mathrm{Z}$ chromosome by FISH (Figure 2B). The HSD17B4 BAC clone also cross-hybridized to the $\mathrm{W}$ chromosome, suggesting that the BAC clone contained the zebra finch ZBM (W chromosome repeat sequence)- related sequence $[52,66,67]$.

\section{Northern blot hybridization shows sex difference in mRNA levels}

Northern blot hybridization for male and female whole brain or gonads showed higher expression of HSD17B4 gene in males relative to females (Figure 3). In both the brain and gonads, the male:female ratio of the density of HSD17B4 hybridization was 1.7. In the brain samples, we could confirm that this sex bias was not due to overall differences in RNA levels loaded onto the blot; the male:female ratio of GAPDH control hybridization was 1.1. A similar control measure could not be obtained for the gonads because GAPDH expression levels can differ across tissues and the results here are consistent with previous reports that the zebra finch testes express higher levels of GAPDH than ovaries [68].

\section{Sex differences and song system localization of HSD17B4 mRNA}

In situ hybridization confirmed the presence of HSD17B4 mRNA in the brains of both males and females, at P5 and in adulthood. Brain sections hybridized with the antisense probe showed widespread labeling of cells that express HSD17B4 (Figure 4). As expected, sections hybridized with the negative control sense-configured probes showed no label (Figure 4).

At P5, we detected HSD17B4 hybridization throughout the telencephalon and in the area that resembled the lateral magnocellular nucleus of the nidopallium (LMAN) in male and female brains. This was the only brain area that resembled a song nucleus that was visible at this young age, based on its neuroanatomical position and boundaries (Figure 4). There was no significant sex difference in hybridization density measurements of the entire telencephalon $(p=0.072)$. Within the presumptive LMAN region of P5 birds, however, t-tests showed there was a significant sex difference (male greater than female) in HSD17B4 hybridization intensity $(\mathrm{p}=0.021)$.

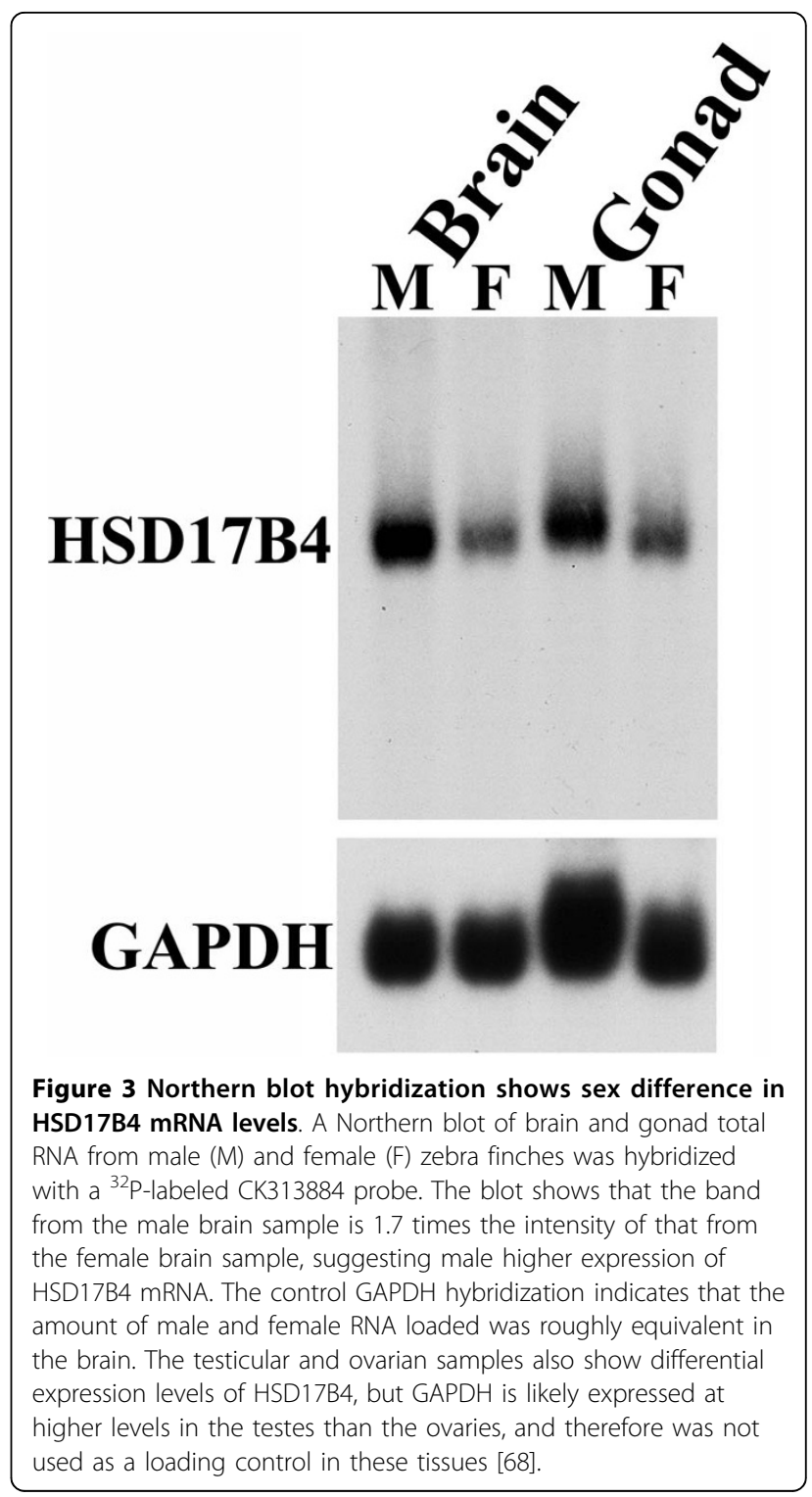

We also detected HSD17B4 mRNA in the adult male HVC (used as a proper name) nucleus of the song circuit, though we were unable to perform a quantitative sex comparison because HVC was not reliably identified in comparable sections in females (Figure 4). Hybridization label in other song areas present in both males and females (LMAN and the robust nucleus of the arcopallium, RA) were not greater than the surrounding telencephalon. Therefore, we analyzed HSD17B4 hybridization intensities on the entire left and right telencephalic lobes in sections that spanned the entire rostral-caudal extent. This analysis revealed significantly higher hybridization levels in the telencephalon of males than of females $(p=0.016)$. 

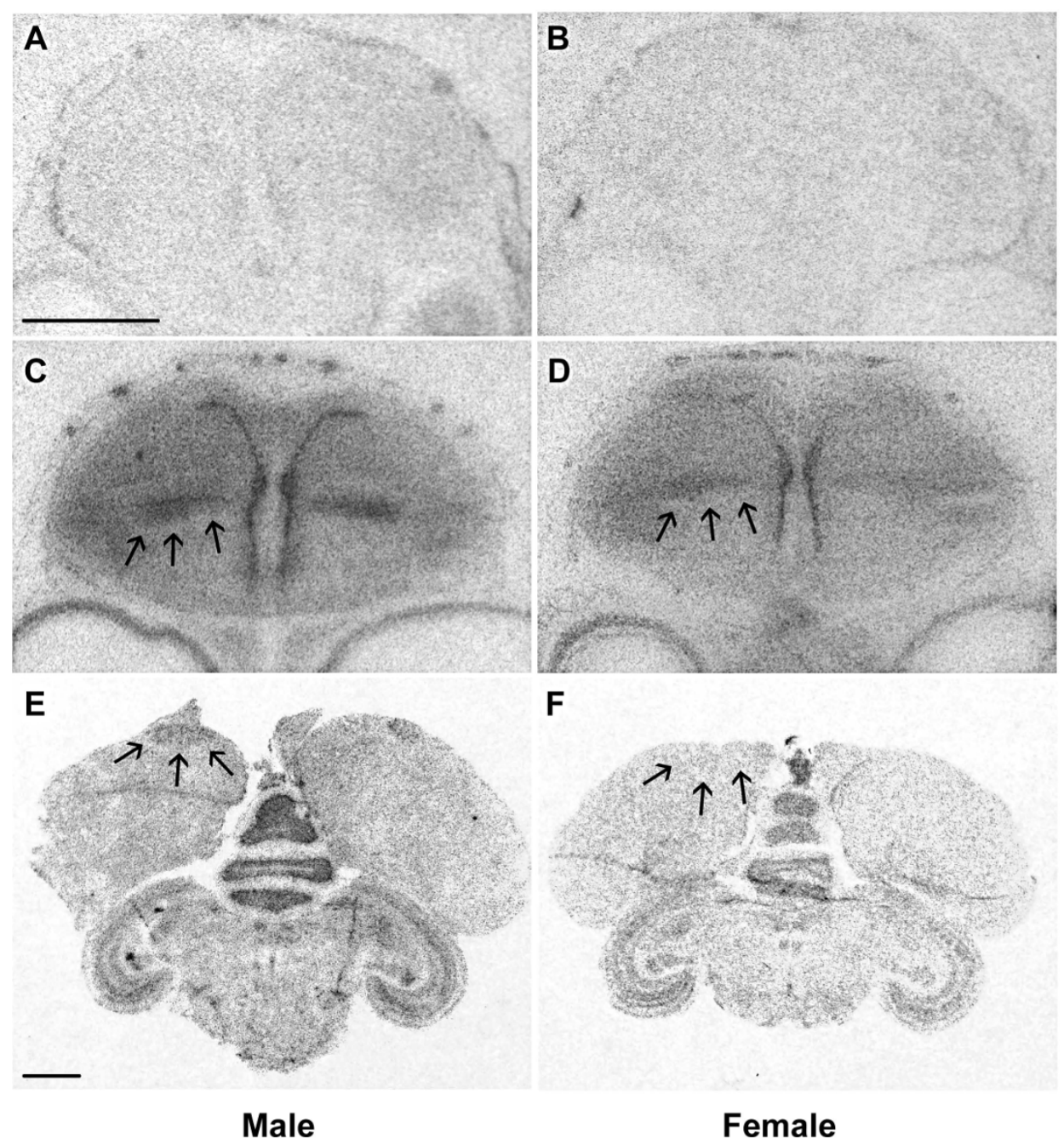

Female

Figure 4 In situ hybridization for HSD17B4 in P5 and adult zebra finch song nuclei. (A, B) Hybridization of P5 male (A) and P5 female (B) brain sections with sense-configured HSD17B4 riboprobe. Absence of detectable labeling demonstrates specificity of hybridization. (C, D) Comparison of HSD17B4 hybridization in P5 male (C) and female (D) brains with antisense-configured riboprobe shows label in the nidopallium where song nucleus LMAN (arrows) is located in adult males. In this region, HSD17B4 shows a significant $(p=0.021)$ sex difference in expression level. (E) HSD17B4 hybridization was also detected in the song nucleus HVC in adult males (arrows). (F) HVC was not visible in adult females (arrows denote area of HVC but no detectable hybridization), but the telencephalic levels of HSD17B4 expression were significantly $(p=0.016)$ higher in adult males than females. Scale bar in $A=1 \mathrm{~mm}$ (applies to A-D), scale bar in E = $1 \mathrm{~mm}$ (applies to E, F).

\section{HSD17B4 activity does not show a sex difference}

Several initial experiments were performed to first optimize the conditions for the final biochemical assessments of HSD17B4 activity in the brain. A timecourse experiment showed that a 5 minute incubation was optimal for accurately measuring HSD17B4 activity (Figure $5 A)$. Presence of an $E_{1}$ cold trap decreased the detectable conversion of $E_{2}$ to $E_{1}$ approximately two-fold (Figure $5 \mathrm{~B})$. Therefore, cold trap was not used in subsequent experiments. Lastly, a concentration gradient determined that $50 \mathrm{nM}{ }^{3} \mathrm{H}-\mathrm{E}_{2}$ was the optimum substrate concentration for measuring HSD17B4 activity after 5 minutes of incubation (Figure 5B).
Using the optimized conditions, we first analyzed HSD17B4 activity in the telencephalon and diencephalon of adult male and female birds. Two-way ANOVA for sex, region and the sex by region interaction showed that there was no significant overall effect of sex ( $\mathrm{p}=$ $0.745)$, brain region $(\mathrm{p}=0.206)$, or the interaction $(\mathrm{p}=$ 0.263) on HSD17B4 activity levels (Figure 6A).

In a separate set of birds, we performed another assay for HSD17B4 activity in two telencephalic regions that contained brain regions that in situ hybridization and Northern blot results suggested would have HSD17B4 activity (dorsomedial telencephalon, "DT" and caudodorsal telencephalon, "CT"; details of the dissections in 


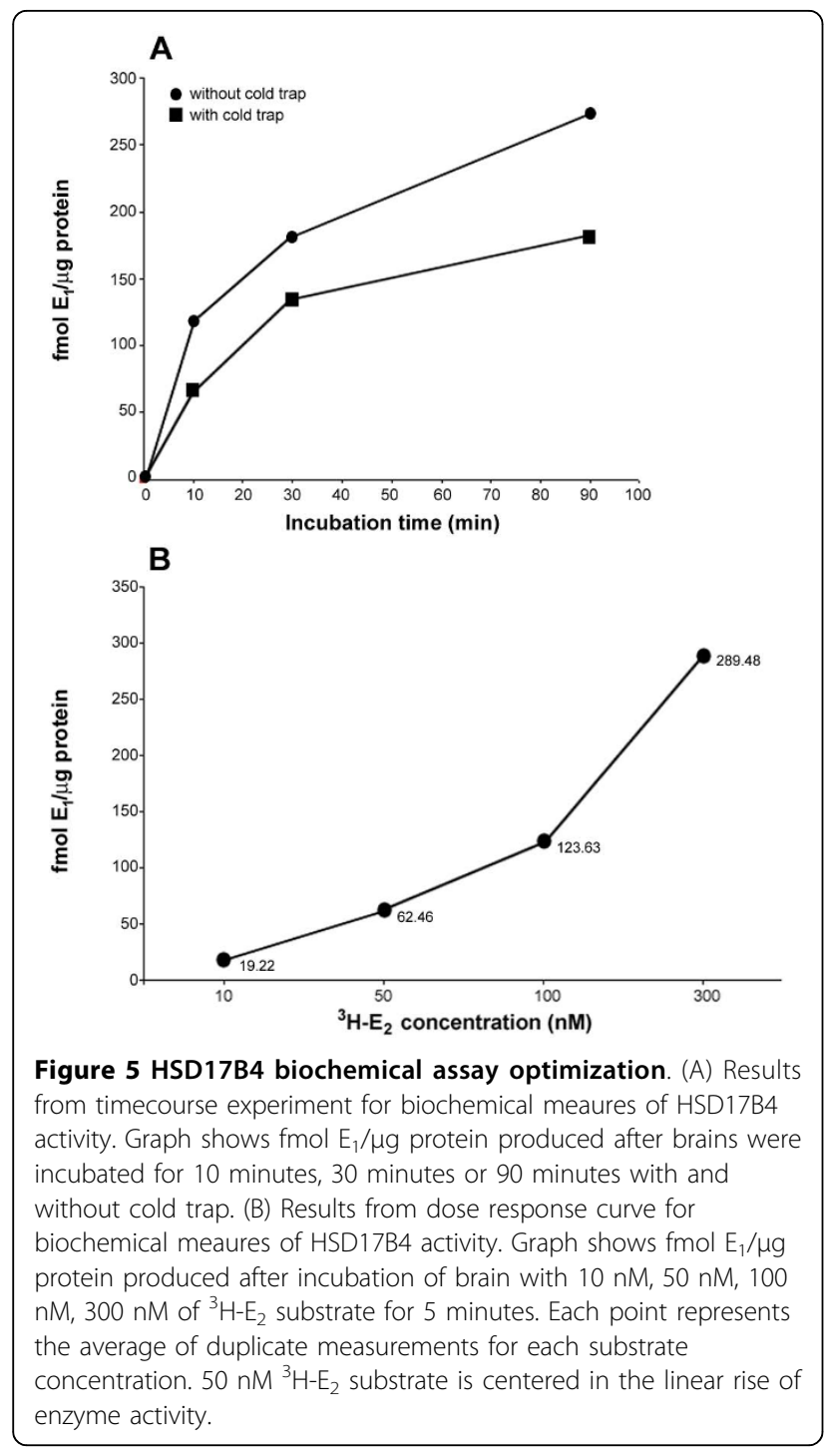

Methods), diencephalon, and gonads (Figure 6B, C). In this experiment, we found that the gonads contained significantly more HSD17B4 activity than the brain $(\mathrm{p}<$ 0.001 ). When the three brain areas were then analyzed for effects of age, sex, and their interaction, we found again that sex had no significant main effect on HSD17B4 activity levels $(p=0.323)$. Individual $t$-tests for the effect of sex within each of the three brain areas also did not detect a sex difference in any individual region (DT: $\mathrm{p}=0.362, \mathrm{CT}: \mathrm{p}=0.151$, diencephalon: $\mathrm{p}=$ $0.106)$. In this assay, we did detect a significant main effect of brain area $(\mathrm{p}=0.001)$. Post-hoc analysis demonstrated that the effect of brain area was due to higher levels of HSD17B4 activity in the diencephalon compared to the two telencephalic regions. Further, there was a significant interaction between sex and brain area $(\mathrm{p}=0.043)$. The interaction occurred because
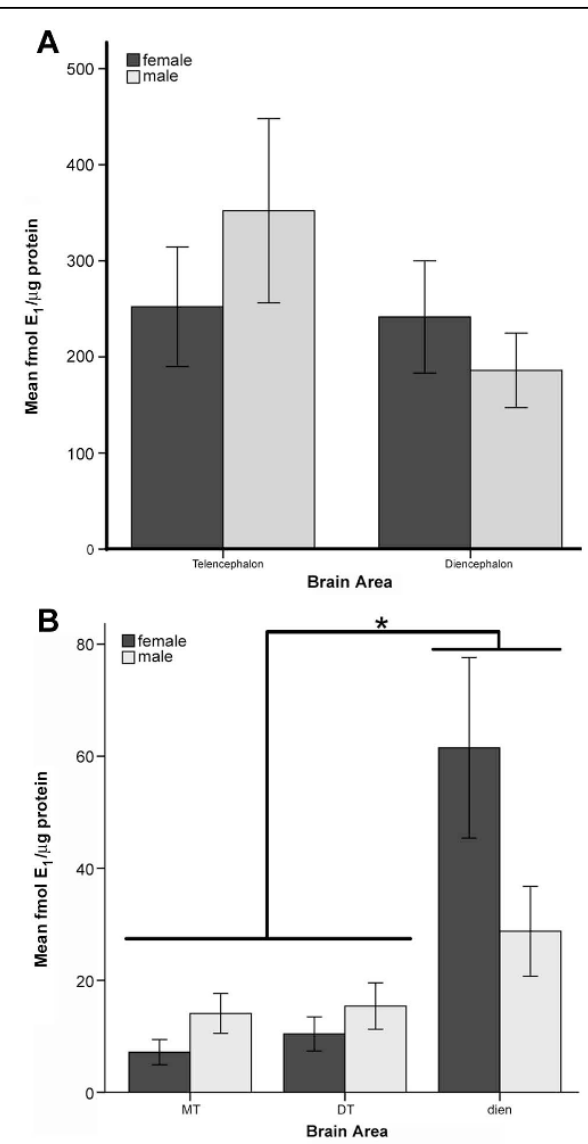

C

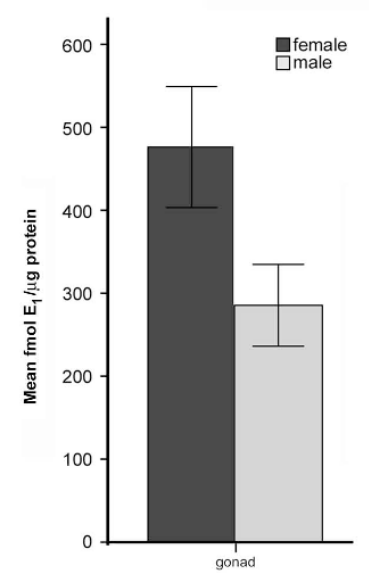

Figure 6 Results of biochemical assays for HSD17B4 activity in male and female brain regions from two experiments. (A) Comparison of HSD17B4 activity in whole telencephalon and diencephalon shows no significant differences between sex, brain region, or the interaction of sex by brain region. There is a subtle trend in the male towards higher activity in the telencephalon compared to male diencephalon and both female regions. (B) Comparison of HSD17B4 activity in two sub-regions of the telencephalon and the diencephalon showed no overall sex differences but a significant sex by brain area interaction $(p=0.017)$. (C) HSD17B4 activity levels measured in testes and ovaries are significantly higher than those in the brain $(p<0.001)$ but do not show a significant sex difference $(p=$ 0.062). Error bars are \pm s.e.m. 
in the diencephalon, we measured higher (but not significantly higher) HSD17B4 activity levels in the female $\left(61.5 \pm 36.06 \mathrm{fmol} \mathrm{E}_{1} / \mu \mathrm{g}\right.$ protein) compared to the male $\left(28.7 \pm 18.06 \mathrm{fmol} \mathrm{E}_{1} / \mu \mathrm{g}\right.$ protein) but in the two telencephalic regions, HSD17B4 activity levels were higher in the male (CT: $14.1 \pm 7.1$, DT: $15.4 \pm 9.3 \mathrm{fmol}$ $\mathrm{E}_{1} / \mu \mathrm{g}$ protein) than in the female (CT: $7.2 \pm 4.5$, DT: $10.4 \pm 6.8 \mathrm{fmol} \mathrm{E}_{1} / \mu \mathrm{g}$ protein; Figure $\left.6 \mathrm{~B}\right)$.

\section{Discussion}

Estradiol is a potent masculinizing steroid for the developmental growth of the sexually dimorphic song circuit in the zebra finch. Estradiol also continues to impact the function of song regions in adult birds [69]. Unlike most sexually dimorphic systems, gonadal secretions do not control song circuit masculinization. Consequently, two non-exclusive theories have been proposed to explain the sex difference in the song circuit: the neural production of steroids and the differential expression of sex chromosome genes in the brain. Here, we examined $\mathrm{HSD} 17 \mathrm{~B} 4$, an $\mathrm{E}_{2}$-metabolizing enzyme mapped to the $\mathrm{Z}$ sex chromosome, as an example of how these two theories might converge.

We confirmed the $\mathrm{Z}$ chromosome localization of the HSD17B4 gene, and that the abundance of HSD17B4 DNA and brain mRNA is approximately two-times greater in males a than in females, consistent with previous reports [50,57]. Based on in situ hybridization signal distributions here and in a previous study, it may be that HSD17B4 has a specific role in the sexual differentiation and function of the song circuit. Here, we showed that in the first week of posthatch development when $E_{2}$ is most effective for masculinizing the song nuclei, HSD17B4 expression is detectable in the P5 brain and expression levels are higher in an area that appears to be LMAN in males than in females. If this is indeed LMAN, it would be the earliest identification of this nucleus in the zebra finch. Further, the LMAN expression appears to be developmentally regulated; in P25 birds, HSD17B4 hybridization intensity in LMAN was also higher than in the adjacent telencephalic tissue but there was no significant sex difference within the song nucleus, and by adulthood, label was not noticeably greater in LMAN than in the surrounding brain [50]. In contrast, we were able to detect HSD17B4 mRNA in the HVC of adult males (but not females), where HSD17B4 mRNA has been shown to be significantly enriched compared to the surrounding telencephalon in P25 and adult males [50,70]. This song nucleus also contains synaptic aromatase that can be modulated by song production, thus both aromatase and HSD17B4 may together regulate the availability of $\mathrm{E}_{2}$ in the adult $\mathrm{HVC}[2,4,39]$.
The higher levels of HSD17B4 expression in the male brain compared to the female brain, in particular within song control nuclei, were counterintuitive given extensive evidence that $E_{2}$ masculinizes these areas [24]. Nevertheless, the higher expression of HSD17B4 mRNA in males than females was consistent with previous findings that many $\mathrm{Z}$ chromosome genes are poorly dosage compensated in birds; the majority of genes on the $\mathrm{Z}$ chromosome show higher mRNA levels in males (ZZ) than females (ZW) $[51,66]$. The incomplete dosage compensation in birds differs strikingly from the effective dosage compensation patterns found in other species $[48,66]$. It is generally accepted, however, that dosage compensation is critical and ubiquitous among species with heteromorphic sex chromosomes like the avian $\mathrm{Z}$ and $\mathrm{W}[48,71-73]$. Thus, it was possible that dosage compensation could occur via post-transcriptional mechanisms in the zebra finch.

We therefore assayed the activity levels of HSD17B4 in adult brains. Our results demonstrate that this enzyme is active in metabolizing $E_{2}$ in the zebra finch. However, in two major brain regions and in two experiments, the conversion of $E_{2}$ to $E_{1}$ was not significantly different between adult males and females - the sex difference in HSD17B4 mRNA levels in the adult brain does not translate into a sex difference in activity levels. Therefore, while the neuroanatomical mapping of HSD17B4 mRNA suggested that this enzyme may influence the sex-specific organization and function of the song control circuit by reducing the availability of $E_{2}$ in males, our biochemical results indicate that post-transcriptional mechanisms may regulate neural HSD17B4 activity to minimize the sex difference found in HSD17B4 expression levels.

Perhaps regulatory mechanisms that are known to modify enzyme activity, such as phosphorylation and availability of substrate or cofactors, could explain our results. These factors might override the tendency for greater enzyme activity based on the male bias in mRNA abundance. Enzymes in particular have been theorized to be relatively dosage insensitive because their function is often more strongly dependent on properties other than the copy number of the genes encoding them [74]. Steroidogenic enzyme regulation may have been especially relevant to the evolution of an $\mathrm{E}_{2}$-sensitive neural circuit such as the zebra finch song system. The precise mechanisms that control, and the functional significance of, this region-specific regulation of HSD17B4 activity remains to be discovered.

\section{Conclusions}

HSD17B4 is a Z-linked enzyme that shows a sex difference in DNA dose and mRNA expression levels, but not 
in activity levels. The post-transcriptional regulation of HSD17B4 may signal that $E_{2}$ metabolism is tightly controlled in the brains of both male and female zebra finches.

\section{Methods}

All zebra finches were obtained from colonies housed in the UCLA Life Science Vivarium. The Chancellor's Animal Research Committee approved all protocols.

\section{HSD17B4 gene and CDNA clone annotation}

Two zebra finch HSD17B4 cDNA clones were independently produced and used for probe templates in subsequent experiments. We cloned one cDNA from zebra finch brain using PCR and plasmid cloning techniques as previously described [6]. Primers used to amplify the cDNA were: S: 5'-TTTTCCACCCAAGAGACCCC-3' AS: 5'-TGGCATAGTCTTTCAGGATCATTTC-3'. This clone was used as the riboprobe template for in situ hybridization experiments. After we had obtained this clone, the Songbird Neurogenomics Initiative (SoNG) cloned a HSD17B4 expressed sequence tag as part of a brain transcriptome project (EST; GenBank Accession No. CK313884) [60]. We obtained this clone and used it for the probe template for BAC library screening, Southern blot and Northern blot hybridizations. We compared the sequence of the two cDNA clones to determine that they largely overlap and therefore provided comparable measures of HSD17B4 DNA and mRNA across the experiments.

At the time both clones were produced, their identities as HSD17B4 sequences were based on homology matches to genes in other species such as human and chicken. To do this, we aligned the predicted amino acid sequence of the EST to the predicted amino acid sequence of the human, chicken, zebra fish and mouse HSD17B4 genes to assess the extent that the zebra finch sequence shares sequence and functional domain motifs with known HSD17B4 genes from other species.

Recently, the zebra finch genome has been sequenced and assembled [64]. Therefore, to further confirm the clone identities, we compared their nucleotide sequences to a model of the zebra finch gene sequence we constructed from the genome assembly. To create this model, we used DNA sequence from the zebra finch genome assembly, the EST sequence from the ESTIMA database and the sequence of our cloned cDNA, the set of RefSeq GenBank entries from other species, and the predicted human HSD17B4 protein coding sequence. With this information, we manually curated the HSD17B4 predicted gene sequence and structure in the Apollo Genome Annotation Curation Tool [63]. We then aligned the zebra finch brain cDNA clone sequences to the genomic sequence to identify the gene region included in the clones; we show the structural alignment of the gene to the SoNG EST sequence here.

\section{Southern blot hybridization}

Zebra finch genomic DNA for Southern blot analysis was isolated from heparinized blood. Briefly, the nuclei of blood cells were suspended in $10 \mathrm{mM}$ Tris- $\mathrm{HCl}(\mathrm{pH}$ 8.0), $100 \mathrm{mM}$ EDTA (pH 8.0) and incubated in the presence of $0.5 \%$ sodium dodecyl sulfate (SDS), $100 \mu \mathrm{g} / \mathrm{ml}$ proteinase $\mathrm{K}$ at $50^{\circ} \mathrm{C}$ overnight. The mixture was extracted successively with phenol saturated with TE [10 mM Tris- $\mathrm{HCl}$ (pH 8.0), $1 \mathrm{mM}$ EDTA] and chloroform. The supernatant was ethanol precipitated, washed with $70 \%$ ethanol and resolved in TE. The purified genomic DNA was stored at $4^{\circ} \mathrm{C}$ until use.

Male or female genomic DNA was digested HindIII or HaeIII, then electrophoresed in a $1 \%$ agarose gel, $1 \times$ TAE $(4 \mu \mathrm{g} /$ lane). The gel was denatured with $0.5 \mathrm{M}$ $\mathrm{NaOH}-1.5 \mathrm{M} \mathrm{NaCl}$ for 30 minutes, rinsed in water and neutralized in $1 \mathrm{M}$ Tris $(\mathrm{pH} 7.6)-1.5 \mathrm{M} \mathrm{NaCl}$ for 30 minutes. After another wash in $20 \times$ SSC for 20 minutes, the gel was transferred to MAGNA Nylon Transfer membrane (Osmonics Inc, Minnetonka, MN) in 20x SSC overnight. The membrane was washed in $2 \times$ SSC, dried and baked at $80^{\circ} \mathrm{C}$, then UV cross linked. The DNA for probes was agarose gel purified from restriction enzyme digested plasmids using the Gene Clean kit (Q-BIOgene, Solon, OH). Hybridization with a ${ }^{32} \mathrm{P}-$ labeled DNA probe was carried out in a hybridization buffer $[0.5 \mathrm{~mol} / \mathrm{L}$ Na-phosphate buffer (pH 7.2), 7\% SDS, $1 \mathrm{mmol} / \mathrm{L}$ EDTA, 1\% BSA (A3059, Sigma, St. Louis, MO)] at $65^{\circ} \mathrm{C}$ overnight. The membrane was washed in $2 \times \mathrm{SSC}, 0.1 \%$ SDS at room temperature for 1 minute twice and $65^{\circ} \mathrm{C}$ for 30 minutes twice, and then subjected to autoradiography.

Hybridization was performed with an expressed sequence tag (EST) clone from the ESTIMA database (GenBank Accession No. CK313884) that was identified as HSD17B4. Before using CK313884 as a probe in any of these experiments, we first confirmed its identity by comparing it to known HSD17B4 sequences in other species and confirming known conserved functional domains (MOTIF, http://motif.genome.jp/.

\section{Fluorescent in situ hybridization (FISH)}

The HSD17B4 zebra finch bacterial artificial chromosome (BAC) clone, 094L04, was isolated from a zebra finch BAC library made by the Arizona Genomics Institute http://www.genome.arizona.edu after hybridization with CK313884 probe. Isolation of BAC DNA, chromosome preparation and FISH to mitotic chromosomes prepared from zebra finch fibroblasts were carried out according to the methods of Itoh and Arnold [75]. 


\section{Northern blot hybridization}

RNAs for male and female adult zebra finch brain or gonads were isolated using Trizol (Invitrogen, Carlsbad, CA) according to manufacturer's instructions, and stored at $-80^{\circ} \mathrm{C}$ until use. RNA samples $(8 \mu \mathrm{g} /$ lane $)$ were subjected to denaturing agarose gel electrophoresis and capillary transferred to a MAGNA Nylon Transfer membrane (Osmonics Inc) in 10× SSC. The membrane was hybridized with a ${ }^{32} \mathrm{P}$-labeled probe based on CK313884, in the same hybridization buffer used for Southern blot hybridization (above), at $68^{\circ} \mathrm{C}$ for 12 hours. After hybridization, the membrane was washed in $2 \times$ SSC, $0.1 \%$ SDS at room temperature for 5 minutes twice, $1 \times \mathrm{SSC}, 0.1 \% \mathrm{SDS}$ at $37^{\circ} \mathrm{C}$ for 15 minutes twice and $65^{\circ} \mathrm{C}$ for 15 minutes twice, and finally subjected to autoradiography. After hybridization for HSD17B4, the blots were stripped and re-hybridized for GAPDH as an RNA loading control.

The density of the bands for brain and gonad samples was quantified in Image J http://rsbweb.nih.gov/ij/. The density of the region of the blot surrounding the band was subtracted from the density of the hybridized band to normalize for any differences in background. This process was performed for bands hybridized with the HSD17B4 probe and the GAPDH probe. We report male:female density ratios except in the case of GADPH hybridization to the gonads, which was higher in testes than in ovaries, as in a previous report [68].

\section{In situ hybridization and analysis}

P5 and adult brains were collected, flash frozen, and stored at $-80^{\circ} \mathrm{C}$ until use. Delicate P5 brains were retained in the skull to prevent damage from dissection. Both male and female brains from each age $(n=4$ per sex for P5, $\mathrm{n}=6$ per sex for adults) were sectioned to $20 \mu \mathrm{m}$ for in situ hybridization. The sex of P5 birds was verified with visual inspection of the gonads. Prior to hybridization, slides were dried at room temperature for 1 hour, then processed as previously described in London et al., 2003 [6]. Male and female sections from each age were processed together to facilitate quantitative comparisons of male and female hybridization levels at P5 and adult. Slides were hybridized overnight at $60^{\circ} \mathrm{C}$ with $4 \times 10^{6} \mathrm{cpm}$ of either antisense- or sense- configured ${ }^{33} \mathrm{P}$-UTP labeled riboprobes. The probe template was a 761 bp zebra finch HSD17B4 clone independently created from the EST described above, but that overlaps with nucleotides 36-796 of the CK313884 sequence.

After hybridization, slides were washed and dehydrated as previously described [6]. The high stringency wash was performed at $63^{\circ} \mathrm{C}$ for 30 minutes. Slides were dried at room temperature at least 2 hours, then exposed to Kodak MR film (Kodak, Rochester, NY). Film was exposed for $\sim 17$ hours for adult brains, $\sim 4$ days for P5 brains at room temperature, before developing. Slides were subsequently dipped in liquid photographic emulsion, developed 9-10 days later, dehydrated and coverslipped.

To quantify optical density of select brain regions, digital pictures of film exposures were first converted to grayscale in Adobe Photoshop, then the average density of each region was measured in Scion Image http:// www.scioncorp.com/pages/scion_image_windows.htm. Background density was also measured and subtracted from the original density, giving the overall mean density. Quantification of telencephalic hybridization intensities was performed on a series of sections approximately $100 \mu \mathrm{m}$ apart that spanned the rostral to caudal extent of the telencephalon; the entire lobe of the telencephalon was included from both left and right hemispheres in all sections that contained telencephalon. This data was then analyzed with t-tests (SSPS, SSPS Inc., Chicago, IL) to test for significant sex differences in hybridization intensities.

\section{Image production}

In situ hybridization images from BioMax MR films were captured with a Zeiss Stemi 2000-C dissecting scope mounted with an AxioCam MRc digital camera with MRGrab 1.0 software (Carl Zeiss Inc., Thornwood, NY). Southern and Northern blot film images were captured by scanning into an EPSON Expression 800 flatbed scanner.

\section{HSD17B4 activity}

To measure HSD17B4 activity in brain tissues, we used the core biochemical procedure previously described for other steroidogenic enzymes [19,22,30,39,40,76-78]. Briefly, tissue was homogenized in sucrose phosphate buffer ( $\mathrm{pH}$ 9.0). Aliquots from the homogenates are added to $3 \mathrm{mM}$ nicotinamide adenine dinucleiotide (NAD+) cofactor and tritiated $\mathrm{E}_{2}\left({ }^{3} \mathrm{H}-\mathrm{E}_{2}\right)$ substrate, and incubated at $41^{\circ} \mathrm{C}$. Enzymatic activity was stopped by flash freezing. Steroids were purified from proteins via repeated ether extractions. To separate individual steroids, samples were spotted on thin layer chromatography (TLC) plates after the addition of non-radiolabeled $E_{1}$ and $E_{2}$ to facilitate steroid visualization. TLC plates were resolved in a 3:1 ether:hexane mixture. Separated bands identified as $E_{1}$ and $E_{2}$ from standard samples were scraped from the TLC plates, eluted into methanol, and ${ }^{3} \mathrm{H}$-estrogens were directly quantified in a liquid scintillation counter. To normalize the quantity of steroid produced to the mass of protein in each sample, a Bradford protein assay was performed with the protein fraction of the homogenates. All sample tubes were run in triplicate, and " $\mathrm{S}$ " tubes that contained no tissue and an " $R$ " tube that contained only ${ }^{3} \mathrm{H}-\mathrm{E}_{2}$ were included to 
assay background levels of metabolite and percent recovery of steroids, respectively. The total quantity of ${ }^{3} \mathrm{H}-\mathrm{E}_{1}$ synthesized in each reaction was calculated by subtracting background values from the total ${ }^{3} \mathrm{H}-\mathrm{E}_{1}$ counts per minute (cpm) for each sample, and dividing this value by the percent recovery of each assay. Values are reported as femtomoles of ${ }^{3} \mathrm{H}$-steroid per microgram of protein (fmol $E_{1} / \mu g$ protein).

Since the activity levels of HSD17B4 enzyme have not previously been studied in the zebra finch, we first performed several experiments to optimize conditions for its measurement. To determine the most accurate period of tissue incubation, we performed a timecourse experiment. We used two adult female whole brains, and after homogenization, samples were incubated with $100 \mathrm{nM}{ }^{3} \mathrm{H}-\mathrm{E}_{2}$ and incubated at $41^{\circ} \mathrm{C}$ for 10,30 , or 90 minutes. Results were plotted to determine a time of linear activity levels. To determine if the addition of an $\mathrm{E}_{1}$ "cold trap," radioinert $\mathrm{E}_{1}$, would enhance the detection of ${ }^{3} \mathrm{H}-\mathrm{E}_{1}$ by limiting the conversion of ${ }^{3} \mathrm{H}-\mathrm{E}_{1}$ to other steroid products, $1 \mu \mathrm{g} \mathrm{E} \mathrm{E}_{1}$ was added to half of the tubes in a preliminary experiment. Lastly, to determine the optimal ${ }^{3} \mathrm{H}-\mathrm{E}_{2}$ concentration to use for substrate, a female whole brain was incubated in the presence of 10 , 50,100 , or $300 \mathrm{nM}^{3} \mathrm{H}-\mathrm{E}_{2}$ and processed as above.

Utilizing the conditions determined by preliminary experiments (5 minute incubation with $100 \mathrm{nM}^{3} \mathrm{H}-\mathrm{E}_{2}$ and no cold trap), we then performed two experiments to measure the HSD17B4 activity in dissected brain areas. First, we assayed HSD17B4 levels in the telencephalon and diencephalon of adult males and females ( $\mathrm{n}$ $=5$ per sex). Second, we further dissected the telencephalon into two parts: the dorsomedial telencephalon ("DT," tissue between the midline and $2 \mathrm{~mm}$ lateral to midline starting $5 \mathrm{~mm}$ from the rostral tip of the brain and terminating $5 \mathrm{~mm}$ from the caudal end of the telencephalon, a region that contains the hippocampus and lateral ventricles), and the caudodorsal telencephalon ("CT," a $1.5 \mathrm{~mm}$ deep section containing the caudal half of the dorsal telencephalon that contains HVC). We also assayed the diencephalon, ovaries and testes from each bird ( $\mathrm{n}=5$ per sex, except CT $\mathrm{n}=4$ per sex due to technical issues). One- and two-way ANOVA and Tukey post-hoc tests (SPSS) were used to test for effects of sex and brain region on HSD17B4 activity.

\section{Acknowledgements}

We thank Kathy Kampf for excellent technical assistance. All authors have read and approved the manuscript. This project was supported by NIH R01 MH061994 (to BAS).

\section{Author details}

${ }^{1}$ Interdepartmental Program in Neuroscience, University of California at Los Angeles, Los Angeles, CA, USA. ²Department of Physiological Science, University of California at Los Angeles, Los Angeles, CA, USA. ${ }^{3}$ Laboratory of
Neuroendocrinology of the Brain Research Institute, University of California at Los Angeles, Los Angeles, CA, USA. ${ }^{4}$ Department of Ecology and Evolutionary Biology, University of California at Los Angeles, Los Angeles, CA, USA. ${ }^{5}$ Institute for Genomic Biology, University of Illinois at UrbanaChampaign, Urbana, IL, USA.

\section{Authors' contributions}

SEL designed experiments, interpreted data, wrote the manuscript and created figures; YI designed, conducted, and interpreted experiments, wrote the manuscript and created figures; VAL, PW, PSE, and RKO conducted experiments; APA, and BAS designed experiments, interpreted data, and wrote the manuscript. All authors read and approved the manuscript.

Received: 24 November 2009 Accepted: 1 April 2010

Published: 1 April 2010

\section{References}

1. Nottebohm F, Arnold AP: Sexual dimorphism in vocal control areas of the songbird brain. Science 1976, 194:211-213.

2. Peterson RS, Yarram L, Schlinger BA, Saldanha CJ: Aromatase is presynaptic and sexually dimorphic in the adult zebra finch brain. Proc Royal Society B: Biol Sci 2005, 272:2089-2096.

3. Remage-Healey L, Maidment NT, Schlinger BA: Forebrain steroid levels fluctuate rapidly during social interactions. Nat Neurosci 2008, 11:1327-1334.

4. Remage-Healey L, Oyama RK, Schlinger BA: Elevated aromatase activity in forebrain synaptic terminals during song. J Neuroendocrinol 2009, 21:191-199.

5. Rohmann KN, Schlinger BA, Saldanha CJ: Subcellular compartmentalization of aromatase is sexually dimorphic in the adult zebra finch brain. Dev Neurobiol 2007, 67:1-9.

6. London SE, Boulter J, Schlinger BA: Cloning of the zebra finch androgen synthetic enzyme CYP17: a study of its neural expression throughout posthatch development. J Comp Neurol 2003, 467:496-508.

7. London SE, Monks DA, Wade J, Schlinger BA: Widespread capacity for steroid synthesis in the avian brain and song system. Endocrinol 2006, 147:5975-5987.

8. Holloway CC, Clayton DF: Estrogen synthesis in the male brain triggers development of the avian song control pathway in vitro. Nat Neurosci 2001, 4:170-175.

9. Grisham W, Mathews GA, Arnold AP: Local intracerebral implants of estrogen masculinize some aspects of the zebra finch song system. $J$ Neurobiol 1994, 25:185-196.

10. Jacobs EC, Arnold AP, Campagnoni AT: Developmental regulation of the distribution of aromatase- and estrogen-receptor-mRNA-expressing cells in the zebra finch brain. Dev Neurosci 2000, 21:453-472.

11. London SE, Schlinger BA: Steroidogenic enzymes along the ventricular proliferative zone in the developing songbird brain. J Comp Neurol 2007, 502:507-521.

12. London SE, Remage-Healey L, Schlinger BA: Neurosteroid production in the songbird brain: A re-evaluation of core principles. Front Neuroendocrinol 2009, 30:302-314.

13. Remage-Healey L, London SE, Schlinger BA: Birdsong and the neural production of steroids. J Chem Neuroanatomy 2010, 39:72-81.

14. Saldanha CJ, Tuerk MJ, Kim YH, Fernandes AO, Arnold AP, Schlinger BA: Distribution and regulation of telencephalic aromatase expression in the zebra finch revealed with a specific antibody. J Comp Neurol 2000, 423:619-630.

15. Schlinger BA, Arnold AP: Brain is the major site of estrogen synthesis in a male songbird. Proc Natl Acad Sci USA 1991, 88:4191-4194.

16. Schlinger BA, Arnold AP: Circulating estrogens in a male songbird originate in the brain. Proc Natl Acad Sci USA 1992, 89:7650-7653.

17. Schlinger BA, Soma KK, London SE: Neurosteroids and brain sexual differentiation. Trends Neurosci 2001, 24:429-431.

18. Shen P, Campagnoni CW, Kampf K, Schlinger BA, Arnold AP, Campagnoni AT: Isolation and characterization of a zebra finch aromatase cDNA: In situ hybridization reveals high aromatase expression in brain. Mol Brain Res 1994, 24:227-237.

19. Tam H, Schlinger BA: Activities of 3beta-HSD and aromatase in slices of developing and adult zebra finch brain. Gen Comp Endocrinol 2007, 150:26-33. 
20. Gong A, Freking FW, Wingfield J, Schlinger BA, Arnold AP: Effects of embryonic treatment with fadrozole on phenotype of gonads, syrinx, and neural song system in zebra finches. Gen Comp Endocrinol 1999, 115:346-353.

21. Wade J, Springer ML, Wingfield JC, Arnold AP: Neither testicular androgens nor embryonic aromatase activity alters morphology of the neural song system in zebra finches. Biol Reproduction 1996, 55:1126-1132.

22. Wade J, Arnold AP: Functional testicular tissue does not masculinize development of the zebra finch song system. Proc Natl Acad Sci USA 1996, 93:5264-5268.

23. Wade J, Swender DA, McElhinny TL: Sexual differentiation of the zebra finch song system parallels genetic, not gonadal, sex. Horm Behav 1999 36:141-152.

24. Wade J, Arnold AP: Sexual differentiation of the zebra finch song system. Ann N Y Aca Sci 2004, 1016:540-559.

25. Agate RJ, Grisham W, Wade J, Mann S, Wingfield J, Schanen C, Palotie A, Arnold AP: Neural, not gonadal, origin of brain sex differences in a gynandromorphic finch. Proc Natl Acad Sci USA 2003, 100:4873-4878.

26. Grisham W, Tam A, Greco CM, Schlinger BA, Arnold AP: A putative 5 alphareductase inhibitor demasculinizes portions of the zebra finch song system. Brain Research 1997, 750:122-128.

27. Grisham W, Lee J, McCormick ME, Yang-Stayner K, Arnold AP: Antiandrogen blocks estrogen-induced masculinization of the song system in female zebra finches. J Neurobiol 2002, 51:1-8.

28. Mathews GA, Arnold AP: Antiestrogens fail to prevent the masculine ontogeny of the zebra finch song system. Gen Comp Endocrinol 1990, 80:48-58.

29. Arnold AP: Sex chromosomes and brain gender. Nat Rev Neurosci 2004, 5:701-708.

30. Chen X, Agate RJ, Itoh Y, Arnold AP: Sexually dimorphic expression of trkB, a Z-linked gene, in early posthatch zebra finch brain. Proc Natl Acad Sci USA 2005, 102:7730-7735.

31. Cam V, Schlinger BA: Activities of aromatase and 3beta-hydroxysteroid dehydrogenase/delta4-delta5 isomerase in whole organ cultures of tissues from developing zebra finches. Horm Behav 1998, 33:31-39.

32. Jacobs EC, Arnold AP, Campagnoni AT: Zebra finch estrogen receptor cDNA: cloning and mRNA expression. J Steroid Biochem and Mol Biol 1996, 59:135-145.

33. Kim YH, Perlman WR, Arnold AP: Expression of androgen receptor mRNA in zebra finch song system: developmental regulation by estrogen. $J$ Comp Neurol 2004, 469:535-547.

34. Perlman WR, Arnold AP: Expression of estrogen receptor and aromatase mRNAs in embryonic and posthatch zebra finch brain. J Neurobiol 2003 55:204-219.

35. Perlman WR, Ramachandran B, Arnold AP: Expression of androgen receptor $m R N A$ in the late embryonic and early posthatch zebra finch brain. J Comp Neurol 2003, 455:513-530.

36. Schlinger BA, Amur-Umarjee S, Campagnoni AT, Arnold AP: 5 betareductase and other androgen-metabolizing enzymes in primary cultures of developing zebra finch telencephalon. J Neuroendocrinol 1995, 7:187-192

37. Wade J, Schlinger BA, Arnold AP: Aromatase and 5 beta-reductase activity in cultures of developing zebra finch brain: an investigation of sex and regional differences. J Neurobiol 1995, 27:240-251.

38. Adkins-Regan E, Mansukhani V, Seiwert C, Thompson R: Sexual differentiation of brain and behavior in the zebra finch: Critical periods for effects of early estrogen treatment. J Neurobiol 1994, 25:865-877.

39. Rohmann KN, Schlinger BA, Saldanha CJ: Subcellular compartmentalization of aromatase is sexually dimorphic in the adult zebra finch brain. $J$ Neurobiol 2006, 67:1-9.

40. Simpson HB, Vicario DS: Early estrogen treatment alone causes female zebra finches to produce learned, male-like vocalizations. J Neurobiol 1991, 22:755-776.

41. Simpson HB, Vicario DS: Early estrogen treatment of female zebra finches masculinizes the brain pathway for learned vocalizations. J Neurobiol 1991, 22:777-793.

42. Wade J, Arnold AP: Post-hatching inhibition of aromatase activity does not alter sexual differentiation of the zebra finch song system. Brain Res 1994, 639:347-350
43. Grisham W, Park SH, Hsia JK, Kim C, Leung MC, Kim L, Arnold AP: Effects of long-term flutamide treatment during development in zebra finches. Neurosci Letters 2007, 418:92-96.

44. Mathews GA, Brenowitz EA, Arnold AP: Paradoxical hypermasculinization of the zebra finch song system by an antiestrogen. Horm Behav 1988, 22:540-551.

45. Schlinger BA, Arnold AP: Androgen effects on the development of the zebra finch song system. Brain Res 1991, 561:99-105.

46. Wade J, Springer ML, Wingfield JC, Arnold AP: Neither testicular androgens nor embryonic aromatase activity alters morphology of the neural song system in zebra finches. Biol Reprod 1996, 55:1126-1132.

47. Agate RJ, Choe M, Arnold AP: Sex differences in structure and expression of the sex chromosome genes CHD1Z and CHD1W in zebra finches. Mol Biol Evol 2004, 21:384-396.

48. Arnold AP, Itoh Y, Melamed E: A Birds-Eye View of Sex Chromosome Dosage Compensation. Annu Rev Genomics Hum Genet 2008, 9:109-127.

49. Wade J, Tang YP, Peabody C, Tempelman RJ: Enhanced gene expression in the forebrain of hatchling and juvenile male zebra finches. J Neurobiol 2005, 64:224-238.

50. Tomaszycki ML, Peabody C, Replogle K, Clayton DF, Tempelman RJ, Wade J: Sexual differentiation of the zebra finch song system: Potential roles for sex chromosome genes. BMC Neurosci 2009, 10:24.

51. Ellegren $H$, Hultin-Rosenberg $L$, Brunstrom B, Dencker L, Kultima K, Scholz B: Faced with inequality: chicken do not have a general dosage compensation of sex-linked genes. BMC Biol 2007, 5:40.

52. Itoh Y, Kampf K, Arnold AP: Comparison of the chicken and zebra finch $Z$ chromosomes shows evolutionary rearrangements. Chromosome Res 2006, 14:805-815

53. Melamed E, Arnold AP: Regional differences in dosage compensation on the chicken Z chromosome. Genome Biol 2007, 8:R202.

54. Forlano PM, Schlinger BA, Bass AH: Brain aromatase: new lessons from non-mammalian model systems. Front Neuroendocrinol 2006, 27:247-274.

55. Hojo Y, Murakami G, Mukai H, Higo S, Hatanaka Y, Ogiue-lkeda M, Ishii H, Kimoto T, Kawato S: Estrogen synthesis in the brain-role in synaptic plasticity and memory. Mol Cell Endocrinol 2008, 290:31-43.

56. Woolley CS: Estrogen-mediated structural and functional synaptic plasticity in the female rat hippocampus. Horm Behav 1998, 34:140-148.

57. Itoh $Y$, Kampf $K$, Arnold AP: Comparison of the chicken and zebra finch $Z$ chromosomes shows evolutionary rearrangements. Chrom Res 2006, 14:805-815.

58. Gahr M, Metzdorf $R$ : The sexually dimorphic expression of androgen receptors in the song nucleus hyperstriatalis ventrale pars caudale of the zebra finch develops independently of gonadal steroids. J Neurosci 1999, 19:2628-2636.

59. Kim YH, Perlman WR, Arnold AP: Expression of Androgen Receptor mRNA in Zebra Finch Song System: Developmental Regulation by Estrogen. J Comp Neurol 2004, 469:535-547.

60. Replogle K, Arnold AP, Ball GF, Band M, Bensch S, Brenowitz Dong S, Drnevich J, Ferris M, George JM, Gong G, Hasselquist D, Hernandez AG, Kim R, Lewin HA, Liu L, Lovell PV, Mello CV, Naurin S, Rodriguez-Zas S, Thimmapuram J, Wade J, Clayton DF: The Songbird Neurogenomics (SoNG) Initiative: Community-based tools and strategies for study of brain gene function and evolution. BMC Genomics 2008, 9:134.

61. Adamski J, Leenders F, Carstensen JF, Kaufmann M, Markus MM, Husen B, Tesdorpf JG, Seedorf U, de Launoit Y, Jakob F: Steroids, fatty acyl-CoA, and sterols are substrates of $80-k D a$ multifunctional protein. Steroids 1997 62:159-163.

62. Normand T, Husen B, Leenders F, Pelczar H, Baert JL, Begue A, Flourens AC, Adamski J, de Launoit Y: Molecular characterization of mouse 17 betahydroxysteroid dehydrogenase IV. J Steroid Biochem Mol Biol 1995, 55:541-548.

63. Lewis SE, Searle SM, Harris N, Gibson M, Lyer V, Richter J, Wiel C, Bayraktaroglir L, Birney E, Crosby MA, Kaminker JS, Matthews BB, Prochnik SE, Smithy CD, Tupy JL, Rubin GM, Misra S, Mungall CJ, Clamp ME: Apollo: a sequence annotation editor. Genome Biol 2002, 3:RESEARCH0082.

64. Warren WC, Clayton DF, Ellegren $H$, Arnold AP, Hillier LW, Kunstner A, Searle S, White S, Vilella AJ, Heger A, Kong L, Ponting CP, Jarvis E, Mello CV, Minx $P$, Yang S-P, Lovell $P$, Velho TAF, Ferris M, Balakrishnan CN, Sinha $S$, Blatti C, London SE, Li Y, Lin Y-C, George J, Sweedler J, Southey B, 
Gunaratne P, Watson M, Nam K, Backstrom N, Smeds L, Nabholz B, Itoh Y, Howard J, Pffenning A, Whitney O, Völker M, Skinner BM, Griffin DK, Ye L, Flicek P, Quesada V, Velasco G, Lopez-Otin C, Puente XS, Oleander T, Lancet D, Villela A, Smit AFA, Hubley R, Konkel M, Walker JA, Batzer MA, Gu W, Pollock DD, Chen L, Cheng G, Eichler E, Stapley J, Slate J, Ekblom R, Burt D, Scharff C, Adam I, Richard H, Sultan M, Soldatov A, Graves T, Fulton L, Nelson J, Chinwalla A, Hou S, Mardis ER, Wilson RK: The genome of a songbird. Nature

65. Leenders F, Dolez V, Begue A, Moller G, Gloeckner JC, de Launoit, Adamski J: Structure of the gene for the human 17beta-hydroxysteroid dehydrogenase type IV. Mamm Genome 1998, 9:1036-1041.

66. Itoh Y, Melamed E, Yang X, Kampf K, Wang S, Yehya N, Van Nas A, Replogle K, Band MR, Clayton DF, Schadt EE, Lusis AJ, Arnold AP: Dosage compensation is less effective in birds than in mammals. J Biol 2007, 6:2.

67. Itoh Y, Kampf K, Arnold AP: Molecular cloning of zebra finch W chromosome repetitive sequences: Evolution of the avian $\mathrm{W}$ chromosome. Chromosoma 2008, 117:111-121.

68. Itoh Y, Kampf K, Arnold AP: Disruption of FEM1C-W gene in zebra finch: Evolutionary insights on avian ZW genes. Chromosoma 2009, 118:323-334.

69. Remage-Healey L, Coleman MJ, Oyama RK, Schlinger BA: Brain estrogens rapidly strengthen auditory encoding and guide song preference in a songbird. Proc Natl Acad Sci USA 107(8):3852-7.

70. Lovell PV, Clayton DF, Replogle KL, Mello CV: Birdsong "transcriptomics": Neurochemical specializations of the oscine song system. PLOS ONE 2008 , 3:e3440.

71. Gilfillan GD, Straub T, de Wit E, Greil F, Lamm R, van Steensel B, et al: Chromosome-wide gene-specific targeting of the Drosophila dosage compensation complex. Genes Dev 2006, 20:858-870.

72. Gupta V, Parisi M, Sturgill D, Nuttall R, Doctolero M, Dudko OK, Malley JD, Eastman PS, Oliver B: Global analysis of X-chromosome dosage compensation. J Biol 2006, 5:3.

73. Nguyen DK, Disteche CM: Dosage compensation of the active $X$ chromosome in mammals. Nat Genetics 2006, 38:47-53.

74. Kacser H, Burns JA: The molecular basis of dominance. Genetics 1981, 97:639-666.

75. Itoh Y, Arnold AP: Chromosomal polymorphism and comparative painting analysis in the zebra finch. Chrom Res 2005, 13:47-56.

76. Cam V, Schlinger BA: Activities of aromatase and 3ß-hydroxysteroid dehydrogenase/ $\Delta 4-\Delta 5$ isomerase in whole organ cultures of tissues from developing zebra finches. Horm Behav 1998, 33:31-39.

77. Freking F, Nazairians T, Schlinger BA: The expression of the sex steroidsynthesizing enzymes CYP11A1, 3beta-HSD, CYP17, and CYP19 in gonads and adrenals of adult and developing zebra finches. Gen Comp Endocrinol 2000, 119:140-151.

78. Schlinger BA, Lane NI, Grisham W, Thompson L: Androgen synthesis in a songbird: a study of cyp17 (17alpha-hydroxylase/C17,20-lyase) activity in the zebra finch. Gen Comp Endocrinol 1999, 113:46-58.

doi:10.1186/1471-2202-11-47

Cite this article as: London et al:: Neural expression and post-

transcriptional dosage compensation of the steroid metabolic enzyme 17ß-HSD type 4. BMC Neuroscience 2010 11:47.

\section{Submit your next manuscript to BioMed Central and take full advantage of:}

- Convenient online submission

- Thorough peer review

- No space constraints or color figure charges

- Immediate publication on acceptance

- Inclusion in PubMed, CAS, Scopus and Google Scholar

- Research which is freely available for redistribution

Submit your manuscript at www.biomedcentral.com/submit 